\title{
Reviewing the Knowledge Systems of Innovation and the Associated Roles of Major Stakeholders in the Indian Context
}

\author{
Punit Saurabh, Prabha Bhola, and Kalyan Kumar Guin
}

\author{
"For good ideas and true innovation, you need human") \\ interaction, conflict, argument, debate.
}

\author{
Margaret Heffernan \\ Entrepreneur and author
}

\begin{abstract}
In this article, we review various models of knowledge systems and discusses the relationships between various component stakeholders of innovation, namely higher-education institutions, industry, and government. The article uses India as a case study to examine new challenges and opportunities facing its innovation ecosystem. Within this context, we review existing models of knowledge systems through an innovative representation exemplifying the knowledge landscape and the model positioning. We argue for a reinforcing role of major stakeholders in the proliferation of innovation and entrepreneurship, and the need to promote healthy interactions between them.
\end{abstract}

\section{Introduction}

To address the challenge of creating jobs and wealth in modern economies, governments promote innovation because of its perceived contributions to the creation of jobs and wealth (Orhan \& Scott, 2001). In particular, to fuel job creation, governments worldwide encourage students in higher-education institutions to consider entrepreneurship as an alternative to traditional employment. Indeed, there has been an increasing emphasis on entrepreneurship as a career option, especially during the recent global economic recession, which provided a boost to the types of course offerings in higher-education institutions and led to an upswing in student enrolment (Solomon, 2007). Recently, higher-education institutions have been offering an increasing number of courses related to entrepreneurship, especially in the United States during the difficult economic periods between 1996 and 1999 (Kuratko, 2005), when student attendance in entrepreneurial courses increased by $92 \%$ (Solomon, 2007).

Because of their role in entrepreneurship education, higher-education institutions can be viewed as societal innovation systems. Their task is not only to produce entrepreneurially oriented and competent individuals, but also to foster social mechanisms that underpin and facilitate the birth and growth of businesses and firms at a regional level (Laukkanen, 2000). Through regional innovation-based practices, higher-education institutions are increasingly acting as centers of growth and are poised to play a prominent role in economic development. This new, broader role has also opened up new challenges and opportunities for higher-education institutions, particularly in emerging countries (Gupta, 2005).

Lundvall and colleagues (2002) found that the efficiency of knowledge activities depends on the innovation system and its performance on several aspects of socio-economic and political institutions. They characterized knowledge systems and their relationship with economic development and innovation by interconnecting them with the introduction of knowledge into the economy and the society at large. Numerous researchers (e.g., Edquist et al., 2000; Parikh, 2001) also link knowledge systems to innovation. And, the link between entrepreneurial activity and economic growth has been made by several researchers (Caree \& Thurik, 2002), who recognize the relevance of entrepreneurial activity and innovation in the economic development of a nation. Thus, there is a subtle linkage existing 


\section{Reviewing the Knowledge Systems of Innovation and the Roles of Major Stakeholders} Punit Saurabh, Prabha Bhola, and Kalyan Kumar Guin

between innovation and knowledge systems. Others (e.g., Lundvall et al., 2002; Reynolds et al., 2002) have also referred to the interconnectivity of innovation and entrepreneurship, and the resultant role of other knowledge system stakeholders, specifically the role of higher-education institutions in economic growth.

In the present article, we use India as a case study to examine new challenges and opportunities facing its innovation ecosystem and the role played by higher-education institutions and other knowledge system stakeholders The Indian context is unique due to its demographic, geographic, and socio-economic positioning. India is the second most populous nation and has a fledgling economy with consumer appetite for all types of market-driven goods and services. It has vast diversities of religion, castes, and sects with a complex mix of problems echoing the severity of sub-Saharan African nations, which often lack the basic necessities of food, health, education, safe drinking water, etc. while in contrast matching the capabilities of developed nations with rapid strides in the field of high technology and software. Yet, the challenges are grave and look insurmountable unless serious remedial actions are initiated.

We provide background information about the Indian context in terms of barriers to innovation and identify a key collaboration gap in the innovation ecosystem: a lack of interaction between innovation stakeholders. As a potential means to fill this gap, we examine the role of knowledge systems by reviewing some of the models available in the literature. The article highlights the role of major stakeholders and points to the perceived gaps of the Indian innovation ecosystem and the role of knowledge systems in an Indian context. The knowledge system landscape indicates the positioning of the existing knowledge system models highlighted in the literature review. The ideal roles of major stakeholders in the innovation construct has been highlighted from an Indian perspective, which is pro-development and allinclusive, but it is also relevant to other similarly placed economies.

\section{Literature Review: Knowledge Systems}

Parikh (2001) describes knowledge systems as consisting of four important knowledge processes: identification, preparation, documentation, and actualization. Primarily, the categorization of knowledge systems aims to support knowledge transformation suitable for its distribution and sharing among stakeholders. Scientific and technological developments have had con- siderable impact on socio-economic processes of change of technological innovations (Leydesdorff \& van den Besselaar, 1994). Correspondingly, socio-economic conditions also play an important role in research and development $(\mathrm{R} \& \mathrm{D})$ based decision processes within the knowledge systems, especially in the industrial sector. Several conceptual models and approaches to linking innovation to important constituents of knowledge systems and the economy have evolved.

Pol and Carroll (2006) have argued in favour of knowledge system as a critical dimension of economic change with components of innovation, entrepreneurial activities, and market power playing an important role. Comparatively, Drucker (1985) considered innovation as "a specific instrument of the entrepreneur" and an "output of knowledge-based systems". For Lindley (2003), a knowledge system, much like a society, is "a process of structural change leading to the production diffusion and use of knowledge in the economy with a potential to play a major role in wealth creation". Twarog (2003) describes knowledge systems as entities comprised of research systems, higher-education institutions, industries and governments, policy making bodies, and R\&D labs that integrate several factors of innovations and its respective aiding mechanisms.

Leydesdorff and Meyer (2006) refer to a knowledgebased innovation system as: "an outcome of interaction among different social coordination mechanisms like markets, knowledge production, and governance at interfaces". Edquist (1997) states that a knowledge system might remain active at different levels (e.g., industrial, local, regional, national, and international). According to Etzkowitz and Leydesdorff (2000), knowledge system models are indication of flux and the rearrangement and widening of the role of knowledge in society and the economy. Nine of these conceptual models and approaches to understanding innovation as an important constituent of knowledge systems and economies are summarized in Table 1.

\section{Representing the Knowledge System Landscape}

Notwithstanding the interface of innovation, a need was felt to represent the existing knowledge system models, leading to the conceptualization of the knowledge system landscape. The new construct adds another critical dimension, which provides a wide-angle view of several existing knowledge system processes, models, and stakeholders, in addition to their the sub-divisions and its areas of emphasis. 


\section{Reviewing the Knowledge Systems of Innovation and the Roles of Major Stakeholders}

Punit Saurabh, Prabha Bhola, and Kalyan Kumar Guin

Table 1. Summary of key knowledge system models

\begin{tabular}{lll}
\hline Knowledge System Model & Description \\
\hline $\begin{array}{l}\text { National Innovation System } \\
\text { (Lundvall, 1988; Nelson, 1993) }\end{array}$ & $\begin{array}{l}\text { focuses on flows of knowledge, flow of technology, and information among people, } \\
\text { enterprises, and institutions }\end{array}$ \\
\hline $\begin{array}{l}\text { Post-Modern Research System } \\
\text { (Rip \& van der Meulen, 1996) }\end{array}$ & $\begin{array}{l}\text { consists of two systemic aspects of research systems: "steering" (i.e., the degree of } \\
\text { sensitivity when implementing an objective) and "aggregating" (the organization of } \\
\text { processes of agenda building within the system) }\end{array}$ \\
$\begin{array}{ll}\text { analyzes the infrastructure support, quality of support, and other aspects to } \\
\text { determine the quality of research at an institution }\end{array}$ \\
$\begin{array}{ll}\text { Research System in Transition } \\
\text { (Rip, 1990) }\end{array}$ & $\begin{array}{l}\text { refers to the role of R\&D systems as the dynamics of change while laying out an } \\
\text { agenda for future directions of science policy research }\end{array}$ \\
\hline $\begin{array}{l}\text { Mode I } \\
\text { (Gibbons et al., 1994) }\end{array}$ & $\begin{array}{l}\text { refers primarily to basic university research organized in a disciplinary structure } \\
\text { describes a mode of knowledge production whose foundations rest on principles of } \\
\text { scientific expertise, peer review, and non-interference } \\
\text { differentiates itself from scientific discovery of theoretical, experimental science by an } \\
\text { internally-driven taxonomy of disciplines and by the autonomy of scientists and their } \\
\text { host institutions (i.e., the higher-education institutions) }\end{array}$ \\
\hline
\end{tabular}

Mode II

(Carayannis \& Campbell, 2012)

\section{Mode III}

(Carayannis \& Campbell, 2012)
- describes the new production of knowledge featuring production, trans-disciplinary work, high reflexivity, and ingenious methods of quality control

- varies depending on the context, which could differ significantly due to variations in geographical, historical, social, and cultural settings

- refers to open, adaptive, learning-driven knowledge at the foundational level and innovation, and refers it as "a multilayered, multimodal, multinodal, and multilateral system", encompassing mutually complementary and reinforcing innovation networks and knowledge clusters

- comprises clusters of human and intellectual capital, outlined by social capital and underlined by financial capital

\section{Triple Helix}

(Etzkowitz \& Leydesdorff, 2000)

\section{Quadruple Helix}

(Carayannis \& Campbell, 2012)
- refers to a spiral model of innovation that captures multiple reciprocal relationships at different points in the process of knowledge capitalization

- denotes the university-industry-government relationship as one of relatively equal, yet interdependent and overlapping, institutional spheres

- highlights the government, higher-education institutions, industry, and civil society as key actors promoting a democratic approach to innovation through which strategy development and decision-making are exposed from the feedback, leading to policies and practices responsible in a social context

- offers a future-oriented outlook and vision, addressing the current challenges and introducing a problem-solving approach that emphasizes a sustainable development perspective that brings together innovation, entrepreneurship, and democracy

- brings together different and complex perspectives to understand, manage, and govern Mode III as well as the Quadruple and Quintuple Helices

- identifies open innovation diplomacy as a novel strategy

- includes the "media-based and culture-based public" and "civil society" 


\section{Reviewing the Knowledge Systems of Innovation and the Roles of Major Stakeholders}

Punit Saurabh, Prabha Bhola, and Kalyan Kumar Guin

The knowledge system landscape tries to accommodate various existing models that have not been explored in this way before. It also helps clarify the positioning of the existing models in the knowledge system. For example, there are several existing stakeholders of the knowledge systems, including higher-education institutions, industry, government, $R \& D$ labs, funding agencies, venture capitalists, and high-net-worth individuals (HNIs), and civil society. The representation helps clarify the perspectives, functioning, and proximities of differing models as well as their differentiators. In one case, researchers have been able to identify government, higher-education institutions, and industry as major stakeholders of the knowledge systems aptly defined in the Triple Helix model. Referring to this model, Leydesdorff and Meyer (2003) emphasize three different sub-dynamics of knowledge-based innovation systems: economic exchanges in the market, geographical disparities, and the organization of knowledge. Similarly, government, higher-education institutions, industry, and civil society are key actors promoting a democratic approach to innovation emphasized by the Quadruple Helix Model (Carayannis \& Campbell, 2012). The knowledge system landscape provides a pictorial representation of the models and their positioning, as shown in Figure 1. It also helps elucidate the important role played by secondary and tertiary knowledge stakeholders, namely the R\&D labs, government and private funding agencies, high-net-worth Individuals, social entrepreneurs, nongovernmental organizations (NGOs), and several other crucial stakeholders .

The knowledge system landscape integrates several other associated modules, namely the Post-Modern Research System, Modes I, II, and III, and the National Innovation System, which all have a healthy connectivity with the resources of higher-education institutions and the facilitations of government to aid, promote, and measure research and its outputs. Notably, research and innovation is considered as key to the growth of knowledge systems and hence finds mention in several models, such as the Post-Modern Research

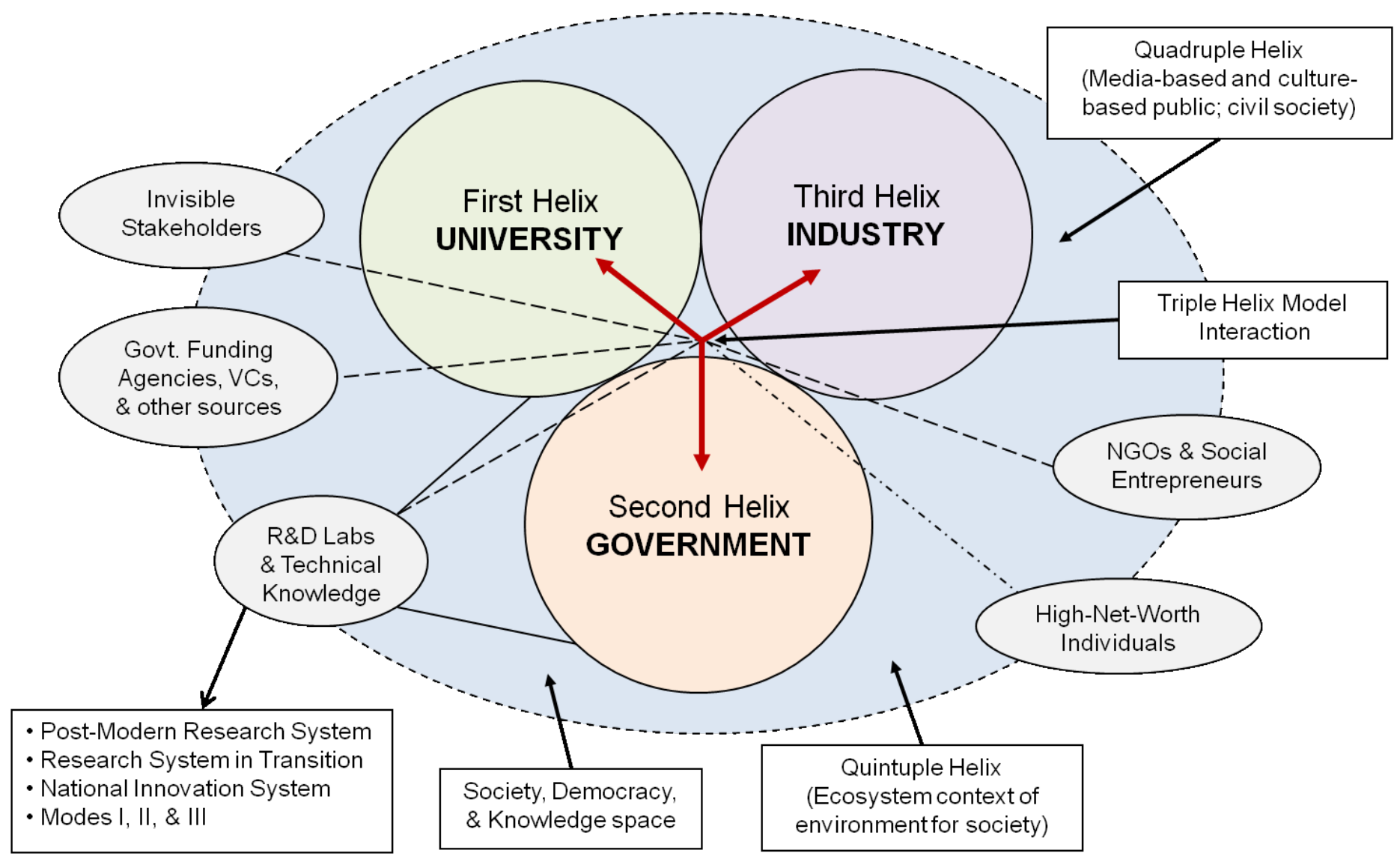

Figure 1. The knowledge system landscape 


\section{Reviewing the Knowledge Systems of Innovation and the Roles of Major Stakeholders} Punit Saurabh, Prabha Bhola, and Kalyan Kumar Guin

System, the National Innovation system, and the Research System in Transition. The knowledge system landscape provides adequate representation of the R\&D labs, as referred to by Rip (1990), who highlighted the essential role of R\&D systems in the Research Systems in Transition model in terms of dynamics of change and a step towards setting an agenda for science policy research. High reflexivity found favor from Nowotny and colleagues (2003) who, while explaining Mode I, note the key role of independence and autonomy provided to researchers at higher-education institutions and research labs in the growth of knowledge systems. The connectivity between the highereducation institutions and research labs is therefore adequately represented. Thus, the knowledge system landscape connects the independent and dependent stakeholders and provides a wider view of the context. In keeping with the construct, we now explore the issues faced by the innovation stakeholders in promoting innovation in an Indian context.

\section{Barriers to Innovation in India within the Context of Knowledge Systems}

In India, the growth and quality of innovation has been a subject of debate for some time (e.g., National Knowledge Commission, 2007). New product development through innovation has not happened at the desired pace in India due to myriad factors. These factors include the developing nature of the Indian economy (Sikka, 1997), an overdependence on the government, and inadequate contributions from higher-education institutions, and industry.

Open Innovation accounts for a fair share of the Government of India's initiatives to help create a global innovations and startups originating in India. However, most of the business incubators and innovation programs that have been set up by the Government of India have only been partially successful in promoting collaborations with industry and higher-education institutions. Lately, efforts have been made by successive governments to promote innovation in higher-education institutions with active industry participation, but they have so far met with little success because the role of industry is generally very restricted to core areas of interest. Industry support for "corporate social responsibility" for open innovations is also negligible due to the government's unfavourable taxation policies. Some of the major obstacles that are generally observed between the stakeholders of innovation in an Indian setting are:
- an absence of joint collaboration mechanisms between higher-education institutions and industries in the area of joint product development and research

- a lack of innovations emerging from higher-education institutions, and a failure to commercialize innovations that do emerge

- a failure of products developed by higher-education institutions to meet the expectations of industry

- the dearth of intellectual property sharing mechanisms between industry and higher-education institutions

- inadequate industry sponsorship for research in specific areas of industrial importance

- a deficiency of infrastructure available at higher-education institutions and in industry, which impairs the development of joint research platforms and mutually beneficial collaborative work

- insufficient orientation in innovation and entrepreneurship orientation provided by schools and highereducation institutions

- a scarcity of trained manpower to groom innovators and foster entrepreneurship, especially in technology parks, which are incubators that are generally based within higher-education institutions

- a want of support programs based in higher-education institutions and managed by their staff to help innovators carry out innovation/product commercialization and entrepreneurship

In several cases the role of a higher-education institution is partially or wholly visible, and hence their role in entrepreneurship comes into focus (Saurabh, 2014). From the above discussion, we conclude that there is a key collaboration gap due to a lack of interaction between the stakeholders of innovation and key players participating in the innovation ecosystem. So far, some of the issues identified above have been addressed by the major stakeholders of innovation, namely highereducation institutions, government, and industry. For example, the government has reformatted and re-conceptualized several innovation funding and support programs for product development and commercialization to support incubation of companies through marketing, intellectual property, and monetary support. 


\section{Reviewing the Knowledge Systems of Innovation and the Roles of Major Stakeholders} Punit Saurabh, Prabha Bhola, and Kalyan Kumar Guin

These efforts have not yet led to overall improvement, as can be observed by the failure of government programs to motivate entrepreneurs and innovators to come up with product- and service-based innovations and startups. A portion of the failures could be attributed to inadequate management practices as well as communication lapses between the innovators, government agencies, support agencies, etc.

\section{Ideal Roles of Indian Innovation Stakeholders}

Several knowledge system models consider higher-education institutions, government, and industry to be the significant stakeholders in innovation creation. In a developing nation such India, the onus for innovation promotion thus lies primarily with the government and the higher-education institutions, with private and public R\&D labs and industry playing supporting roles. All three major stakeholders and their roles in creating an innovation ecosystem in India are discussed in the subsections that follow.

\section{Higher-education institutions}

Higher-education institutions assume greater responsibility than other stakeholders due to their tacit and close relationship with the government and other stakeholders. According to Mansfield and Lee (1996), the role of the university as a key contributor to wealth generation and economic development has increased in recent decades. In the Indian context, there is an increasing need for economic development through provision of better services and infrastructure support for hospitals, roads, electricity, housing, and transportation, etc., which require a highly trained workforce. All of these requirements can be effectively met with a judicious mix of good educational institutions acting as the baseline for knowledge creation at all levels from kindergarten to higher-education institutions. Sadly, there is a dearth of quality higher-education institutions in India to support the demands of the population. India's 2013 ranking in the Global Innovation Index (Dutta \& Lanvin, 2013) for human capital and research stood at a dismal 105th position, which puts it on par with several lower, middle, and underdeveloped economies. The World Bank Institute's (2012) Knowledge for Development report, put India in the 120th position among 145 countries in their knowledge index ranking, which indicates the plight of education and knowledge in India. The need for improving the quality of higher-education institutions is urgently felt.
With growing economic challenges, higher-education institutions in India should no longer remain as factories for producing employees for companies, but should rather focus on nurturing job creators or entrepreneurs. Higher-education institutions should reinvent themselves as potential locations for initiating successful companies by projecting their proximity to industries and advanced research infrastructure. They should focus on innovative research utilizing the available resources, knowledge, and expertise available with faculty members and the student community to promote innovation and entrepreneurial activities within their campuses. Because the vibrant ecosystem around higher-education institutions is rich in technical resources, infrastructure, labour force, and other resources, it is seen as better suited for setting up high-tech industrial clusters, labs, and research centres. Etzkowitz and Leydesdorff (2000) highlight the increasing role of higher-education institutions leading to increased knowledge creation and contributions to economic development. Former Indian Prime Minister Manmohan Singh recently referred to the need for changing the culture in favour of promoting innovation at Indian higher-education and scientific institutions and called for a change in mindsets to promote an innovation culture by aligning with the expectations of the industrial and social sectors (Padma, 2010). He had also emphasized the need to improve the "outward orientation" of higher-education institutions by strengthening links with industry and creating international research partnerships.

Even though India is the second most populous nation in the world, its development in the field of Science and Technology is not visible in its Patent Cooperation Treaty (PCT) rankings in the Global Innovation Index (Dutta \& Lanvin, 2013). For example, India ranked 55th and 54th respectively in domestic resident patent applications and PCT resident patent applications. In terms of the context of innovation in India, a lack of proper orientation during initiation days at education institutions for adopting innovative practices is also a valid reason for higher-education institutions in India not producing patents. Effective steps to generate scientific research outputs leading to patents should be implemented. The higher-education institutions should also generate quality research papers to improve its research and innovation culture at their institutions.

India's 99th place ranking in the Global Innovation Index (Dutta \& Lanvin, 2013) for new businesses in the 


\section{Reviewing the Knowledge Systems of Innovation and the Roles of Major Stakeholders} Punit Saurabh, Prabha Bhola, and Kalyan Kumar Guin

15-64 age group shows the lack of initiative for starting businesses. Higher-education institutions in India do not prepare students for creative thinking, taking on risk, or starting businesses. Hence, entrepreneurial training for students in higher-education institutions should promote a risk-taking attitude, skill development and training, and a general motivation to become entrepreneurial. Higher-education institutions should also provide its student innovators and entrepreneurs with financial support, incubation, technical support, and $R \& D$ lab facilities. Furthermore, product innovation and commercialization support, and venture support in the form of grants or soft loans, will encourage students to take up entrepreneurial work. Higher-education institutions should develop technical expertise in administration and encourage students to take up innovative research while assisting students with their creative efforts. The quality of research must be outstanding to create valuable technology companies for which academic excellence should be promoted.

\section{Government}

Government supported R\&D programs and measures help in escalating economic development. They have the mandate to carry on the activities relating to indigenous technology promotion, development utilization, and transfer. Government-supported R\&D programs in India enable stakeholders to acquire a technology base towards producing quality goods of international standard (Sikka, 1997). In India, due to the absence of major industrial players, the support systems and infrastructure support needed for any plan of action or project, including policy decisions, are designed and supported by the government. It is the government that has to plan the development of industrial parks equipped with modern facilities to host hi-tech, environmentally-sensitive new businesses and industries in the priority sectors. Government plays an increasingly important role in providing a regulatory environment and encouraging innovation. The involvement of higher-education institutions is ever-increasing along with industry through consulting, contract research, and company formation from research based in higher-education institutions (Leydesdorff \& Etzkowitz, 2001) in which role of government is considered central.

Government agencies should focus on actively fostering product- and service-based innovation with a view to developing indigenous capacity. These agencies should support the higher-education institutions to organize awareness programs, conferences, and events with the aim of promoting the processes that contribute to innovation while helping the institutions become self-reliant in all aspects. Encouragement through awards, titles, and monetary support should be provided to innovators and entrepreneurs because they act as motivating factors for both the recipients as well as others. Entrepreneurship and innovation support programs should be actively promoted using all recognized forms of media communication. Government funding bodies should monitor the their programs to ensure that funding is used effectively. Obstacles and regulations that hinder innovation and entrepreneurship activities should be abrogated.

To promote creative and entrepreneurial thinking among students and faculty members, government bodies can provide support and funding to set up entrepreneurship and innovation centres at higher-education institutions. Marketing support required by innovators who have developed technologies and wish to commercialize should be provided separately. Presently, there is no specific program from the Government of India to support new technologies with marketing and commercialization. The government's efforts should be directed to support commercialization of technologies developed in India. Apart from funding, the government should try to assist the entrepreneurs with demonstration opportunities leading to product orders with public sector companies. Also, technical support is a major constraint; innovators and entrepreneurs should be provided with dedicated resources, such as labs or centres where they can receive support without cost or at low cost.

\section{Industry}

Industry provides the necessary push to the advancement of innovations. In India, the role of industry in promoting and encouraging innovation has not been vigorous except for some "big names" such as Reliance Industries, Tata, Wipro, and Mahindra. Within Indian industry, R\&D budgets are still lower than the global average.

A combination of differential components creates significant and durable business value for one or more welldefined product platforms or for cost-effective development of processes and products. Technology transfer and innovation platforms can support customers in building highly sophisticated structures needed for efficient $R \& D$ collaboration, licensing, and open innovation. Industry should be willing to provide access to research labs and infrastructure for employees willing 


\section{Reviewing the Knowledge Systems of Innovation and the Roles of Major Stakeholders} Punit Saurabh, Prabha Bhola, and Kalyan Kumar Guin

to innovate or take up intrapreneurship activities. It should give freedom to its employees to experiment, think creatively, and implement innovative ideas along with their regular work.

The support expected from industry in promoting innovation is rarely provided to higher-education institutions because the level of interaction between industry and these institutions is low. Industry efforts should be geared towards building a strategic knowledge partner through engagement of higher-education institutions and other important stakeholders for joint product development, patent sharing, etc. while helping the higher-education institutions in creating a research base. Efforts are being made by industry organizations to promote innovation and research-related interactions through industry bodies such as the Federation of Indian chambers of Commerce and Industry (FICCI; http://ficci.com/) and the Confederation of Indian Industry (CII; http://cii.in), but these efforts are still in their early stages. An "advanced very large scale integration" (AVLSI) lab at the Indian Institute of Technology Kharagpur (http://conf05.iitkgp.ac.in/avlsi/) is an example of industry-university research collaboration with 15 industry partners and the university participating together in several research projects to generate viable research outputs for the researchers and joint intellectual property and patents for the industry partners.

Globalization has created immense opportunities to leverage high-end technology for developing countries, which can be aptly harnessed through industry collaborations. Industry must change its mindset in favour of innovation. Simultaneously, copyright violation, piracy, and patent infringement should be discouraged.

To promote vigorous collaboration between innovators and industry, industry should create refined products from the R\&D developed by the innovators and provide mentorship in commercialization.. It should take bold steps and play a leading role in encouraging pathbreaking, home-grown technologies by investing in future technologies such as brain-computer interfaces, autonomous cars, and robotics. This approach would considerably help entrepreneurs with the application of available technology with industry feedback and encourage further innovation.

Industry can help innovators and entrepreneurs with funding, mentoring, commercialization support, technical and lab support, customer feedback, refinement, and marketing support, in part through links to higher- education institutions. Industries should look at providing technical and financial support to innovative students and even hiring key students or researchers with relevant ideas or domain expertise.

\section{Conclusion}

On the basis of a new representation of the landscape of various knowledge system models, this article has argued that the promotion of innovation is dependent on the roles of various important stakeholders in the knowledge system, which has been highlighted using the Indian context. With the increasing need for innovation and the new knowledge that is integrated within it, the knowledge system has also become more relevant in the current context. Due to the changing role of knowledge systems, the historical proximities and constituents of the various models and subsystems emphasize different aspects and highlight the importance of understanding the roles played by key stakeholders. Only by promoting healthy interactions between government, industry, and higher-education institutions can innovation and entrepreneurship proliferate to the benefit of the Indian innovation ecosystem.

\section{About the Authors}

Punit Saurabh recently completed his $\mathrm{PhD}$ in the domain of innovation and entrepreneurship development from the Indian Institute of Technology Kharagpur, India. He has hands-on experience in managing government innovation and entrepreneurship funding programs and is also involved with the academic aspects of entrepreneurship.

Prabha Bhola is an Assistant Professor in the Rajendra Mishra School of Engineering Entrepreneurship at the Indian Institute of Technology Kharagpur, India, where she also received her PhD in Poverty Economics. She has wide range of teaching experience at different institutions.

Kalyan Kumar Guin is Dean and Professor at the Vinod Gupta School of Management, Indian Institute of Technology Kharagpur, India. He is an alumnus of IIT Kharagpur and Banaras Hindu University in Varanasi, India, and he is a Fellow of the Indian Institute of Management Bangalore. His teaching interests cover marketing and operations management, and he has a special interest in quantitative modelling of strategic issues in management. 


\section{Reviewing the Knowledge Systems of Innovation and the Roles of Major Stakeholders}

Punit Saurabh, Prabha Bhola, and Kalyan Kumar Guin

\section{References}

Carree, M., \& Thurik, A. R. 2002. The Impact of Entrepreneurship on Economic Growth. In Z. J. Acs \& D. B. Audretsch, International Handbook of Entrepreneurship Research: 437-471. Boston/Dordrecht: Kluwer Academic Publishers.

http://dx.doi.org/10.1007/0-387-24519-7_17

Carayannis, E. G. \& Campbell, D. F. J. 2010. Triple Helix, Quadruple Helix and Quintuple Helix and How Do Knowledge, Innovation and the Environment Relate To Each Other? A Proposed Framework for a Trans-disciplinary Analysis of Sustainable Development and Social Ecology. International Journal of Social Ecology and Sustainable Development, 1(1): 41-69.

http://dx.doi.org/10.4018/jsesd.2010010105

Carayannis, E. G., \& Campbell, D. F. J. 2012. Mode 3 Knowledge Production in Quadruple Helix Innovation Systems. Springer Briefs in Business 7. New York: Springer.

http://dx.doi.org/10.1007/978-1-4614-2062-0_1

Drucker, P. F. 1985. Innovation and Entrepreneurship: Practice and Principles. New York: Harper Business.

Dutta, S., \& Lanvin, B. (Eds.). 2013. The Global Innovation Index 2013. The Local Dynamics of Innovation. Geneva, Ithaca, and Fontainebleau: Cornell University, INSEAD, and WIPO. http://www.wipo.int/freepublications/en/economics/gii/gii_2013.pdf

Edquist, C. (Ed.). 1997. Systems of Innovations: Technologies, Institutions, and Organizations. London: Pinter.

Edquist, C., \& Riddell, C. W. 2000. The Role of Knowledge and Innovation for Economic Growth and Employment in the Information and Communication Technology (ICT) Era. In K. Rubenson \& H. G. Schuetze (Eds.). Transition to the Knowledge Society: Policies and Strategies for Individual Participation and Learning: 29. Vancouver, Canada: Institute for European Studies, University of British Columbia.

Etzkowitz, H., \& Leydesdorff, L. 2000. The Dynamics of Innovation: From National Systems and "Mode 2" to a Triple Helix of University-Industry-Government Relations. Research Policy, 29(2): 109-123.

http://dx.doi.org/10.1016/S0048-7333(99)00055-4

Gibbons, M., Limoges, C., Nowotny, H., Schwartzman, S., Scott, P., \& Trow, M. 1994. The New Production of Knowledge: The Dynamics of Science and Research in Contemporary Societies. Thousand Oaks, CA: Sage Publications.

Gupta, A. 2005. International Trends in Private Higher Education and the Indian Scenario. Research and Occasional Paper Series, CSHE 11.05. University of California, Berkeley: Center for Studies in Higher Education.

http://escholarship.org/uc/item/4ch9m7j0

Kuratko, F. D. 2005. The Emergence of Entrepreneurship Education: Development, Trends, and Challenges. Entrepreneurship Theory and Practice, 29(5): 577-97.

http://dx.doi.org/10.1111/j.1540-6520.2005.00099.x

Laukkanen, M. 2000. Exploring Alternative Approaches in High-Level Entrepreneurship Education: Creating Micro-Mechanisms for Endogenous Regional Growth. Entrepreneurship and Regional Development, 12(1): 25-47.

http://dx.doi.org/10.1080/089856200283072
Leydesdorff, L., \& van den Besselaar, P. (Eds.). 1994. Evolutionary Economics and Chaos Theory: New Directions in Technology Studies. London and New York: Pinter.

Leydesdorff, L,. \& Etzkowitz, H. 2001. The Transformation of University-Industry-Government Relations. Electronic Journal of Sociology, 5(4).

Leydesdorff, L., \& Meyer, M. 2003. The Triple Helix of University-Industry Government Relations: Introduction to the Topical Issue. Scientometrics, 58(2): 191-203.

http://dx.doi.org/10.1007/s11192-007-0200-y

Leydesdorff, L., \& Meyer, M. 2006. Triple Helix Indicators of Knowledge-Based Innovation Systems: Introduction to the Special Issue. Research Policy, 35(10): 1441-1449.

Lindley, R.M. 2003. Knowledge-Based Economies: The European Employment Debate in a New Context. Coventry, UK: Warwick Institute for Employment Research, University of Warwick.

Lundvall, B.- Å. 1988. Innovation as an Interactive Process: From User-Producer Interaction to the National System of Innovation. In G. Dosi (Ed.). Technical Change and Economic Theory: 349. London: Pinter.

Lundvall, B.- Å., Johnson, B., Andersen, E. S., \& Dalum, B. 2002. National Systems of Production, Innovation and Competence Building. Research Policy, 31(2): 213-231. http://dx.doi.org/10.1016/S0048-7333(01)00137-8

Mansfield, E., \& Lee, J.-Y. 1996. The Modern University: Contributor to Industrial Innovation and Recipient of Industrial R\&D Support. Research Policy, 25(7): 1047-58. http://dx.doi.org/10.1016/S0048-7333(96)00893-1

National Knowledge Commission. 2007. Innovation in India. Government of India: National Knowledge Commission.

http://www.knowledgecommission.gov.in/downloads/documents/NKC_Innovation.pdf

Nelson, R. R. (Ed.) 1993. National Innovation Systems: A Comparative Analysis. New York: Oxford University Press.

Nowotny, H., Scott, P., \& Gibbons, M. 2003. Introduction: 'Mode 2' Revisited: The New Production of Knowledge. Minerva, 41(3): 179194.

http://dx.doi.org/10.1023/A:1025505528250

Orhan, M., \& Scott, D. 2001. Why Women Enter into Entrepreneurship: An Explanatory Model. Women in Management Review, 16(5): 232-247.

http://dx.doi.org/10.1108/09649420110395719

Padma, T. V. 2010. Indian Prime Minister Calls for 'Innovation Ecosystem'. SciDev.Net. August 1, 2014:

http://www.scidev.net/en/news/indian-prime-minister-calls-forinnovation-ecosystem--1.html

Parikh, M. 2001. Knowledge Management Framework for High-Tech Research and Development. Engineering Management Journal, 13(3): 27-34.

Pol, E. P., \& Carroll, P. 2006. An Introduction to Economics with Emphasis on Innovation. Innovation Planet.

Reynolds, P. D., Bygrave, W. D., Autio, E., Cox, L. W., \& Hay, M. 2002. Global Entrepreneurship Monitor 2002 Executive Report. Wellesley, MA/London: Babson College/London Business School. 


\section{Reviewing the Knowledge Systems of Innovation and the Roles of Major Stakeholders Punit Saurabh, Prabha Bhola, and Kalyan Kumar Guin}

Rip, A. 1990. An Exercise in Foresight: The Research System in Transition - To What? In S. E. Cozzens, P. Healey, A. Rip, \& J. Ziman (Eds.). The Research System in Transition, 387-401. The Netherlands: Kluwer Academic Publishers.

http://dx.doi.org/10.1007/978-94-009-2091-0_29

Rip, A., \& van der Meulen, B. J. R. 1996. The Post-Modern Research System. Science and Public Policy, 23(6): 343-352.

http://dx.doi.org/10.1093/spp/23.6.343

Saurabh, P. 2014. Education-Enterprise Model for Innovation Based Entrepreneurship Development at Higher Education Institutions in India. Doctoral Thesis, Indian Institute of Technology-Kharagpur.

Sikka, P. 1997. Financing the Development of Indigenous Technology in India. Current Science, 73(5): 406-408.
Solomon, G. 2007. An Examination of Entrepreneurship Education in the United States. Journal of Small Business and Enterprise Development, 14(2): 168-82. http://dx.doi.org/10.1108/14626000710746637

Twarog, S. 2003. Preserving, Protecting and Promoting Traditional Knowledge: National Actions and International Dimensions. Selected Papers on Trade and Development Research Issues for Asian Countries.

World Bank Institute. 2012. Measuring Knowledge in the World's Economies: Knowledge Assessment Methodology and Knowledge Economy Index. Washington, DC: World Bank Institute Knowledge for Development Program.

Citation: Saurabh, P., Bhola, P., \& Guin, K. K. 2014. Reviewing the Knowledge Systems of Innovation and the Associated Roles of Major

Stakeholders in the Indian Context. Technology Innovation Management Review, 4(8): 36-45. http://timreview.ca/article/821

Keywords: knowledge systems, innovation ecosystem, innovation system, government, industry, higher-education institutions, university, entrepreneurship, stakeholders, models 